\title{
ESPAÇO DE AÇÃO DE CRIMINOSOS E SUA CORRELAÇÃO COM A PAISAGEM URBANA: UM ESTUDO DE ANÁLISE CENTROGRÁFICA E DISTRIBUIÇÃO DE ATRATORES PARA O CRIME
}

Antônio Hot Pereira de Faria ${ }^{1}$

Alexandre Magno Alves Diniz ${ }^{2}$ Diego Filipe Cordeiro Alves ${ }^{3}$

Resumo: $O$ presente trabalho tem o objetivo de analisar o espaço de ação de criminosos em série em nível individual, a partir de uma perspectiva longitudinal, realizando estatísticas centrográficas dos eventos perpetrados e analisá-las em relação à paisagem urbana, quanto à distribuição de equipamentos urbanos (facilities), a fim de verificar se esses funcionam como atrativos para o cometimento de crimes. No trabalho, foram utilizadas as técnicas centrográficas de centro médio das ocorrências, distância padrão e a elipse de desvio padrão. A metodologia contou com uma base de dados composta por boletins de ocorrência em Belo Horizonte no período de 01/01/2011 a 31/12/2013. Os resultados apontam um alcance criminal definido para a maioria dos infratores em série e a elipse de desvio padrão permite uma representação que agrega o espaço de ação e a forma de dispersão pelo tecido urbano, permitindo verificar a relação entre a paisagem e a localização dos eventos.

Palavras-chave: Análise Centrográfica. Criminosos em série. Comportamento espacial. Atratores para o crime.

\section{THE CRIMINALS ACTION SPACE AND THEIR CORRELATION WITH URBAN LANDSCAPE: A STUDY OF CENTROGRAPHIC ANALYSIS AND DISTRIBUTION OF CRIME ATTRACTORS}

\begin{abstract}
The present work has the objective of analyzing the action space of serial criminals at the individual level, from a longitudinal perspective, performing central statistics of the events perpetrated and analyzing them concerning the urban landscape, regarding the distribution of facilities, to verify if they work as attractive for the commission of crimes. In the work, the centrographic techniques of the occurrences, standard distance and the standard deviation ellipse were used. The methodology included a database of police records with spatial delimitation in the municipality of Belo Horizonte from 01/01/2011 to 12/31/2013. The results indicate that there is a criminal scope for most serial offenders and the standard deviation ellipse allows a representation that aggregates the action space and the dispersion form by the urban space, allowing to verify the relationship between the landscape and the location of the events.
\end{abstract}

Keywords: Centrographic analysis. Serial criminal. Spatial behavior. Crime attractors.

\footnotetext{
1 Polícia Militar de Minas Gerais, Centro de Pesquisa e Pós-Graduação, Belo Horizonte, Brasil, hot.pmmg@gmailcom, https://orcid.org/0000-0003-0543-7503

2 PUC Minas, Pós-Graduação em Geografia: Tratamento da Informação Espacial, Belo Horizonte, Brasil, alexandremadiniz@gmail.com, https://orcid.org/0000-0002-5649-7736

3 PUC Minas, Pós-Graduação em Geografia: Tratamento da Informação Espacial, Belo Horizonte, Brasil, diegofcalves@gmail.com, https://orcid.org/0000-0003-3461-2657
} 


\section{EL ESPACIO DE ACCIÓN PENAL Y SU CORRELACIÓN CON EL PAISAJE URBANO: UN ESTUDIO DE ANÁLISIS CENTROGRÁFICO Y DISTRIBUCIÓN DE ATRACTORES DE CRIMEN}

Resumen: El presente trabajo tiene el objetivo de analizar el espacio de acción de los delincuentes en serie a nivel individual, desde una perspectiva longitudinal, realizar estadísticas centrales de los eventos perpetrados y analizarlos en relación con el paisaje urbano, con respecto a la distribución de las instalaciones, para verificar si funcionan tan atractivo para la comisión de delitos. En el trabajo, se utilizaron las técnicas centrográficas de las ocurrencias, la distancia estándar y la elipse de desviación estándar. La metodología incluyó una base de datos de registros policiales con delimitación espacial en el municipio de Belo Horizonte del 01/01/2011 al 31/12/2013. Los resultados indican que existe un alcance criminal para la mayoría de los delincuentes en serie y la elipse de desviación estándar permite una representación que agrega el espacio de acción y la forma de dispersión por el espacio urbano, permitiendo verificar la relación entre el paisaje y la ubicación de los eventos.

Palabras clave: Análisis centrográfico. Criminal en serie. Comportamiento espacial. Atractores del crimen.

\section{Introdução}

Os indicadores de criminalidade e violência nos centros urbanos apontam para um crescimento generalizado, porém com ilhas de concentração dos crimes violentos em determinados locais. No Brasil, segundo Beato et al. (2008), a partir de dados do Censo de 2000, do Sistema Único de Saúde e do Centro de Estudos de Criminalidade e Segurança Pública, as regiões metropolitanas de Rio de Janeiro e São Paulo concentram $40 \%$ dos homicídios cometidos no país, embora tenham $18 \%$ da população. Além disso, cerca de $20 \%$ das mortes violentas acontecem em menos de $2 \%$ da área geográfica dos centros urbanos.

Em Belo Horizonte, delimitação espacial do presente estudo, não é diferente, $48 \%$ da área do município concentra $90 \%$ dos crimes, conforme estatísticas da Polícia Militar de Minas Gerais (FARIA; ALVES; ABREU, 2018).

Estudos apontam que o comportamento delinquente é influenciado sobremaneira pelos locais percorridos no cotidiano dos ofensores (ANDERSON; HUGHES, 2009; FELSON; GOTTFREDSON, 1984; WARR, 2005). Nesse contexto, os equipamentos urbanos possuem relevância, pois a distribuição do uso e ocupação do solo no espaço urbano determina espaços com concentração de público, exercício de atividades com circulação de dinheiro, etc., o que potencializa as oportunidades para o cometimento de delitos. As instalações (facilities) funcionam como "atratores" para o crime (crime attractors) (BRANTINGHAM; BRANTINGHAM, 1995). 
Faria; Alves e Abreu (2018) em estudo sobre a ocorrência de atratores para o crime em Belo Horizonte e sua correlação com a incidência criminal de roubo no espaço urbano, verificaram que há dependência espacial entre os eventos de roubo e alguns equipamentos urbanos como estabelecimentos de uso comercial e instituições bancárias. Conforme dados da pesquisa, $72 \%$ dos crimes de roubo ocorreram em um ponto até 100 metros de algum comércio, 95\% até 250 metros e 99\% dos eventos ocorreram até 500 metros de um estabelecimento comercial.

Apesar de existirem teorias e dados empíricos que permitam afirmar que a conformação do ambiente urbano cria espaços propícios para a ocorrência de delitos, tais estudos consideram o conjunto de dados numa perspectiva transversal, não sendo uma verificação do nível individual de comportamento criminal.

A estimação de comportamentos individuais a partir de agregados foi chamada de "falácia ecológica". Robinson em 1950 demonstrou alguns dos problemas envolvidos na utilização de dados agregados para tirar conclusões sobre o comportamento individual. Em conjuntos de dados, os objetos da análise estatística são grupos de pessoas, em vez de indivíduos. Robinson (2009) sugeriu que uma correlação agregada geralmente é uma superestimação da correlação individual.

Diferentemente da análise do fenômeno criminal a partir de pacote de eventos (diferentes autores, que cometeram diversos crimes num determinado recorte espaço-temporal), a análise do espaço de ação de criminosos em nível individual deve considerar a série longitudinal de eventos desencadeados por um único ator.

Assim, o objetivo desse trabalho é analisar, em nível individual, a partir de uma perspectiva longitudinal, os crimes perpetrados por indivíduos contumazes na prática de delitos (criminosos em série), analisando as estatísticas centrográficas dos eventos cometidos e analisá-las em relação à paisagem urbana, quanto à distribuição de equipamentos urbanos (facilities), a fim de verificar se esses funcionam como atrativos para o cometimento de crimes em nível individual, assim como ocorre para pacotes de eventos.

A justificativa para o presente estudo reside no fato de que o conhecimento dos locais em que há maior incidência de crimes contribui para a implementação de políticas públicas de segurança mais adequadas, com enfoque à prevenção criminal, além de incrementar o campo acadêmico de estudos interdisciplinares com dados empíricos sobre o fenômeno da criminalidade. 


\section{Comportamento Espacial do Criminoso}

Nesta seção são abordadas as construções teóricas do comportamento criminoso a partir das contribuições da geografia comportamental.

\section{Utilidade do lugar e espaço de ação}

Wolpert (1965) define conceitos centrais no comportamento de migração, mas que servem como parâmetros de decisão locacional do homem: "1) a noção de utilidade de lugar; 2) a abordagem da teoria de campo para o comportamento de busca; 3) abordagem do ciclo de vida para a formação do limiar" (WOLPERT, 1965, p. 161, tradução nossa). Para o autor, o homem tenderá a se localizar em um lugar cujas características possuem ou prometem um nível de utilidade relativamente maior do que em outros lugares que são distintos para ele. Daí decorre o conceito de utilidade do lugar, que representa um espaço que oferece condições favoráveis para satisfazer as necessidades do homem.

Outro conceito importante da obra de Wolpert (1965) é a ideia de espaço de ação (action space), que se refere ao ambiente subjetivo imediato que é o conjunto de utilidades do lugar que o indivíduo percebe e ao qual ele responde. Essa noção de espaço de ação é semelhante ao conceito de espaço de vida (life space) de Lewin (1951) - o universo do espaço e do tempo em que a pessoa concebe que ele pode ou tem capacidade de se mover (WOLPERT, 1965, p. 163).

O ambiente local do indivíduo não pode, naturalmente, ser confinado ao seu entorno imediato. O espaço de ação pode variar em termos de número e intensidade de contatos do domínio ambiental, que pode ser mais limitado ou extenso, dependendo do espaço de ação dentro do qual as pessoas operam.

Segundo Wolpert (1965), o grau de contato pode ser medido pela taxa de recebimento ou percepção de informação. Comunicações de massa e viagens, comunicação com amigos e parentes, por exemplo, integram o indivíduo em uma configuração espacial mais abrangente, mas que, no entanto, ainda é tendenciosa espacialmente.

Associado à evolução do espaço de ação do indivíduo ao longo do tempo, há um complexo de outras forças institucionais e sociais. As diferenças de sexo, raça, educação formal, renda familiar e status provavelmente se expressarão na área de movimento e escolha. Disso decorre que, embora o espaço de ação seja único para cada indivíduo, é provável que haja uma boa convergência em um número limitado de classes de espaços de ação (WOLPERT, 1965). 
No conceito de Lewin, o comportamento é uma função do espaço vital que, por sua vez, é uma função da pessoa e do meio ambiente. Os aspectos influenciadores do comportamento do ambiente externo (físico e social) são repensados através do espaço vital. Da mesma forma, mas de maneira mais limitada, o espaço de ação pode ser considerado como incluindo o intervalo de escolha ou a área de movimento do indivíduo, que é definido tanto por seus atributos pessoais quanto por seu ambiente. Suas necessidades, movimentações e habilidades acumuladas definem suas aspirações - os canais de comunicação trazem informações sobre as formas alternativas de satisfazer essas aspirações (WOLPERT, 1965).

Assim, o espaço de ação do indivíduo inclui não apenas sua posição atual, mas um número finito de lugares alternativos que se tornam visíveis para ele através de uma combinação de seu esforço de busca e transmissão de comunicações. $O$ espaço de ação refere-se a um conjunto de locais para os quais as utilidades esperadas foram definidas pelo indivíduo.

\section{Mapas Mentais}

Mapas mentais (mental maps), também chamados de mapas cognitivos (cognitive map), são conceituados por Smith; Patterson (1980, p. 205, tradução nossa ) como "uma descrição mental de um ambiente". Segundo Paulsen; Robinson (2004) um mapa cognitivo pode ser pensado como um esboço de um lugar ou área que compreende um conhecimento dos indivíduos sobre esse lugar ou área. Já conforme Canter; Hodge (2000), um mapa mental refere-se a representações internas do mundo que as pessoas usam para encontrar o caminho e tomar decisões sobre o que fazer e onde.

Essas representações internas foram exploradas por psicólogos ambientais, como Ladd (1970), usando um dispositivo para levar as pessoas a desenhar um mapa de esboço de uma área. Como Downs e Stea (1977) e muitos outros mostraram, com base no trabalho seminal de Lynch (1960), essas representações mentais diferem de pessoa para pessoa, relacionando-se estreitamente com a experiência real de ambientes específicos.

Canter; Shalev (2008) e Canter; Hodge (2000) exploraram as representações mentais que as pessoas têm de seus arredores, seguindo os estudos de populações não criminosas. 
Brantingham; Brantingham (1981) referiram o significado dos mapas mentais dos criminosos, com citações diretas do trabalho original de Lynch (1957). Eles se basearam fortemente na teoria das atividades rotineiras (Clarke; Felson, 1993), que parte da hipótese de que os criminosos aprendem sobre as oportunidades de crime ou as buscam, como parte de suas ações legais diárias, visitando amigos, indo para o trabalho, compras, etc. Wiles e Costello (2000) relataram resultados de entrevistas com assaltantes que roubam carros, que dão suporte às especulações anteriores de Brantingham e Brantingham (1981). Os entrevistados indicaram que, mesmo quando viajaram certa distância do local de residência para realizar um crime, os locais onde se deslocaram foram influenciados pelos contatos que eles tinham nessas áreas.

A imagem mental ou "mapa" é derivado da interação entre o armazenamento ativo de informações e a disponibilidade passiva de pistas ambientais. A imagem mental que se forma influencia o que a pessoa pensa ser possível e onde existe essa possibilidade. Este é um processo cíclico em desenvolvimento. A interação com os ambientes, por sua vez, molda as concepções da pessoa. Onde um indivíduo faz várias coisas é um produto do que a pessoa sabe ser possível e onde. Este será um processo dinâmico que levará o ofensor para além das suas "atividades rotineiras" à medida que eles exploram as possibilidades de crime. É fora destes processos dinâmicos que o ofensor seleciona oportunidades para o crime. Portanto, quanto mais se entende sobre os processos psicológicos ambientais, mais se pode modelar e prever o comportamento espacial criminal (CANTER; YOUNGS, 2008).

Um mapa mental não indica necessariamente que um indivíduo tem um conhecimento detalhado de uma área inteira, mas sugere que se tem uma imagem mental da geografia dessa área. Na maioria das vezes, as pessoas têm mapas mentais que são altamente detalhados em algumas áreas e apenas compreensões vagas de outras áreas, em grande parte devido à variação na quantidade de atividades que realizam nos diversos espaços. Esses mapas mentais fragmentados são o resultado da experiência de um indivíduo e são usados para resolver problemas, formar opiniões sobre uma área e ações diretas, como rotas de viagem e hábitos de compras (PAULSEN; ROBINSON, 2004).

Os mapas mentais são formados por duas fontes de informações: a primeira e mais impactante são as experiências individuais, através do conhecimento sobre uma localidade ao percorrer e interagir dentro das áreas; e a segunda, a percepção, 
por meio do conhecimento sobre uma área via mídia e amigos, vendo mapas, lugares na TV, etc.

\section{Espaços de consciência (awareness space)}

Conforme abordado, mapas mentais contemplam áreas em que as pessoas possuem conhecimento geográfico detalhado, outras áreas apenas conhecimento superficial. Em termos de geografia comportamental, as áreas em que um indivíduo tem um conhecimento geográfico detalhado são chamadas espaços de consciência (awareness space). Este é um conceito muito importante para a análise espacial do crime e jornada para o crime (jorney to crime), porque as pesquisas demonstram que uma "área de busca" de infratores em termos de atividade criminosa está dentro de seu espaço de consciência.

Figura 1 - Espaço de consciência e de atividade de criminosos

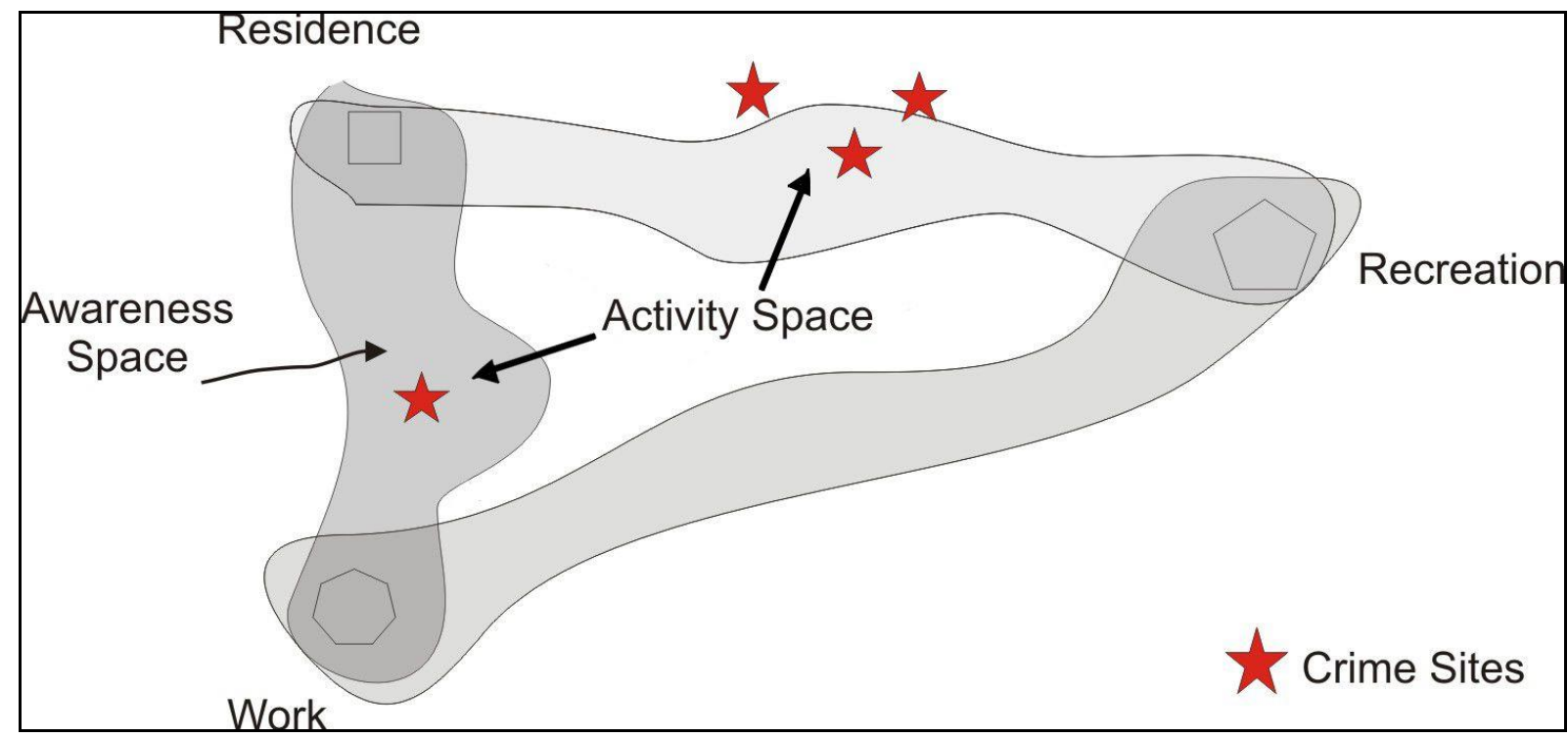

Fonte: FRANK et al. (2011).

Dentro de um mapa mental mais geral dos indivíduos, há uma área mais detalhada do conhecimento espacial (espaço de consciência). É nele que os criminosos procurarão alvos para o cometimento de crimes (BRANTINGHAM; BRANTINGHAM, 1991).

Mapas mentais são desenvolvidos a partir de experiências individuais com seus espaços de consciência. Um espaço de consciência (awareness space) é definido como:

[...] todos os locais sobre os quais uma pessoa tem conhecimento acima de um nível mínimo, mesmo sem visitar alguns deles [...] Espaço de consciência inclui espaço de atividade (a área dentro da qual o indivíduo entra mais frequentemente em contato com outros e com as características 
do ambiente) e sua área se amplia à medida que novos locais são descobertos e/ou novas informações são coletadas (CLARK, 1990, pp. 2425, tradução nossa).

Importante aspecto reside no fato de como um indivíduo adquire seu espaço de consciência. Da mesma forma que ocorre com os mapas cognitivos, o espaço de consciência não é um conceito inerentemente criminoso. Tanto delinquentes quanto os não criminosos obtêm seu espaço de consciência por meio dos mesmos processos gerais de condução de atividades rotineiras (BRANTINGHAM; BRANTINGHAM, 1993).

Segundo Rossmo (1999), a área em que um indivíduo transita regularmente para fins legítimos é denominada seu espaço de atividade (activity space), e está contida no espaço de consciência de um indivíduo. Rossmo (1999) define o espaço de atividade como "os lugares regularmente visitados por uma pessoa na qual a maioria de suas atividades é realizada" (ROSSMO, 1999, p. 255). Este conceito se assemelha ao conceito de espaço de ação de Wolpert (1965), abordado anteriormente.

Um espaço de atividade contém as áreas que compõem a geografia habitual de uma pessoa, composta de locais visitados rotineiramente (diariamente ou semanalmente) e suas vias de conexão (JAKLE; BRUNN; ROSEMAN, 1976).

O tamanho e forma dos espaços de atividade de um indivíduo são determinados pelos pontos de ancoragem (anchor points), conforme o conceito de nós relatado na teoria do padrão criminal de Brantingham e Brantingham e de caminhos (paths), também descritos pelos mesmos autores.

Os pontos de ancoragem referem-se aos locais centrais da vida do indivíduo, como sua casa, local de estudo, trabalho, recreação, etc. Os lugares em que os indivíduos viajam e onde essencialmente realizam suas atividades legítimas ou criminosas. Assim, os nós representam os limites mentais em que os infratores irão buscar por oportunidades criminais.

Em complemento aos pontos de âncora, dois tipos especializados de nós: atrativos de crimes (crime attractors) e geradores de crimes (crime generators), também desempenham um papel na formação do espaço de atividade de um indivíduo e seu espaço de consciência.

Os atrativos de crime são todos os locais, áreas ou vizinhanças onde oportunidades criminais são bem conhecidas e nas quais os delinquentes motivados são posteriormente atraídos como fonte de atividade criminosa (BRANTINGHAM; 
BRANTINGHAM, 1993). Segundo Brantingham e Brantingham (1993), exemplos de atrativos de crimes incluem grandes áreas comerciais que fornecem amplas oportunidades criminais para diferentes infratores. Delitos nestas áreas são frequentemente cometidos por pessoas que vivem fora delas e que viajam grandes distâncias especificamente por causa das oportunidades criminais que existem nos locais (BRANTINGHAM; BRANTINGHAM, 1993).

Já os geradores de crimes são locais e áreas com grandes concentrações de pessoas, as quais são atraídas por razões legítimas, mas que fornecem oportunidades criminais em virtude da oferta de vítimas em potencial (BRANTINGHAM; BRANTINGHAM, 1993). Como exemplo de geradores de crimes tem-se shopping centers, áreas de entretenimento, campi universitários e estádios esportivos, todos que concentram grandes números de vítimas potenciais em horários específicos dentro de áreas concentradas (PAULSEN; ROBINSON, 2004).

Os caminhos são as rotas diárias que as pessoas utilizam para transitar entre diferentes nós (pontos de ancoragem) de atividade. Eles determinam as áreas que um indivíduo vai conhecer através das rotas que percorre. Devido ao fato de as pessoas gastarem muito tempo em rotas entre os nós de atividades, caminhos irão determinar as áreas em que os infratores encontrarão potenciais vítimas (BRANTINGHAM; BRANTINGHAM, 1993).

\section{Análise Centrográfica}

A maior parte das bases teóricas utilizadas para análise do perfil geográfico Espaço de atividade do ofensor (BRANTINGHAM; BRANTINGHAM, 1981), teoria das atividades rotineiras (COHEN; FELSON, 1979), teoria dos padrões de crime (BRANTINGHAM; BRANTINGHAM, 1981), teoria da escolha racional (CORNISH; CLARKE, 1986), decadência à distância (CAPONE; NICHOLS, 1976) -, a partir da criminologia ambiental, pode ser resumida em três conceitos básicos: primeiro, a maioria dos crimes ocorre relativamente perto da residência do agressor; em segundo lugar, a frequência do crime diminui à medida que a distância da casa do agressor aumenta; terceiro, diferentes crimes exibirão diferentes padrões espaciais (KENT; LEITNER, 2007).

Segundo Kent e Leitner (2007), de maneira geral, esses conceitos estabelecem um quadro qualitativo para examinar a relação complexa entre o agressor, o crime e a vítima. Entretanto, como Brantingham e Brantingham (1981) advertiram, não é prático examinar essa relação fora do contexto de lugar. 
Consequentemente, quase todas as metodologias de profissão contemporânea aplicam modelos quantitativos que utilizam, no seu núcleo, princípios geográficos fundamentais. Dois dos princípios mais proeminentes são a centrografia e a difusão espacial (CANTER; LARKIN, 1993; ROSSMO, 1999; SNOOK et al., 2004; SNOOK et al., 2005; LEBEAU, 1987; RICH; SHIVELY, 2004; PAULSEN, 2006). Um resumo destas técnicas e a sua aplicação ao perfil geográfico são fornecidos no Quadro 1:

Quadro 1 - Medidas espaciais utilizadas em Perfil Geográfico Criminal (Criminal Geographic Profiling)

\begin{tabular}{l|l|l|l|l}
\hline Medida & Modelo & Estratégia & Input Modelo & Output Modelo \\
\hline Tendência central & $\begin{array}{l}\text { Média espacial, } \\
\text { mediana e centro } \\
\text { da distância } \\
\text { mínima }\end{array}$ & $\begin{array}{l}\text { Distribuição } \\
\text { Espacial }\end{array}$ & Pontos & Pontos \\
\hline $\begin{array}{l}\text { Dispersão } \\
\text { Espacial }\end{array}$ & $\begin{array}{l}\text { Área de busca } \\
\text { circular; área de } \\
\text { busca elíptica }\end{array}$ & $\begin{array}{l}\text { Distribuição } \\
\text { Espacial }\end{array}$ & Pontos & $\begin{array}{l}\text { Pontos } \\
\text { polígonos es de }\end{array}$ \\
\hline Difusão Espacial & $\begin{array}{l}\text { Algoritmos de } \\
\text { decaimento pela } \\
\text { distância }\end{array}$ & $\begin{array}{l}\text { Distância de } \\
\text { probabilidade }\end{array}$ & Pontos & $\begin{array}{l}\text { Superfícies de } \\
\text { probabilidade }\end{array}$ \\
\hline
\end{tabular}

Fonte: Adaptado de KENT; LEITNER (2007, p. 148).

A aplicação das técnicas centrográficas para o estudo do crime pode ser vislumbrada nas palavras de Kent e Leitner (2007, p. 149, tradução nossa):

As técnicas centrográficas caracterizam fenômenos fornecendo uma única medida de tendência central (ou seja, uma localização média) (LEBEAU, 1987). Essa abordagem constitui uma estratégia de distribuição espacial (LEVINE, 2007). Quando aplicadas a profissões geográficas, essas medidas resumem uma distribuição de cenas de crime a um único local onde a soma das diferenças entre a média e todos os outros pontos dentro da distribuição é zero (EBDON, 1988). A estratégia baseia-se no pressuposto de que o infrator em série cometeu crimes dentro de uma área estreita relativamente próxima da sua casa. Esta área define o espaço de atividade [activity space] do ofensor (BRANTINGHAM; BRANTINGHAM, 1981). Assim, ao se definir o centro da distribuição de um crime, efetivamente revela-se alguma parte do espaço de atividade do agressor.

Assim, a análise centrográfica tem potencial de transformar a massa de dados relativos à atividade criminosa intraurbana em resumos sucintos, que podem ser mais facilmente compreendidos e que permitem isolar certas regularidades em padrões de crime.

Outro aspecto relevante é que a maioria das técnicas geográficas não pode explicar o impacto da paisagem sobre a ocorrência do crime. Os métodos contemporâneos adotam uma suposição a priori de que tanto as cenas de crime quanto a residência do infrator estão localizadas em uma superfície isotrópica, onde a oportunidade de ofensa é distribuída uniformemente em torno da residência do 
agressor (KENT; LEITNER, 2007). Entretanto, conforme estabelecido por Brantingham e Brantingham (1981), e posteriormente por Rengert et al. (1999), a localização de um crime envolve fatores complexos os quais tornam i improvável sua ocorrência aleatória.

No trabalho, foram utilizadas as técnicas centrográficas de centro médio das ocorrências, distância padrão e a elipse de desvio padrão. O objetivo foi de buscar padrões espaciais de distribuição dos eventos e sua relação com a paisagem urbana, com vistas a identificar o espaço de ação dos criminosos em série em Belo Horizonte e sua relação com a distribuição de atratores para o crime no espaço urbano.

\section{Centro Médio da nuvem de pontos}

Considerando o objetivo de se identificar os "espaços de ação" de criminosos reincidentes, buscou-se analisar o centro médio $\mathrm{Cm}$ de ocorrências de eventos criminais. Esta variável representa a média aritmética das coordenadas de longitude e latitude.

O valor $\mathrm{Cm}$ da distribuição espacial de pontos é calculado separando-se as duas médias aritméticas de acordo com as seguintes relações:

$$
\begin{gathered}
\bar{X}_{x}=\frac{\sum_{i=1}^{n} X_{i}}{n} \\
\bar{X}_{y}=\frac{\sum_{i=1}^{n} Y_{i}}{n}
\end{gathered}
$$

Onde $X i$ e $Y i$ são, respectivamente, as coordenadas $X$ e $Y$ de um ponto $i$, e $n$ é o número total de pontos do mapa.

A análise de Centro Médio foi feita para todos os eventos cometidos pelos reincidentes (pacote de dados reincidentes), para todos os eventos de crimes gerais, além da análise individual para cada autor (eventos por autor).

O objetivo desta análise foi permitir a descrição da concentração dos eventos, além de servir de base para análise da "área de atuação" por meio da "distância padrão" e da distribuição direcional, pela "elipse de desvio padrão". Sendo assim, o Centro Médio representa o ponto inicial de análise para as demais técnicas aplicadas. 
Figura 2 - Centro médio da distribuição de pontos

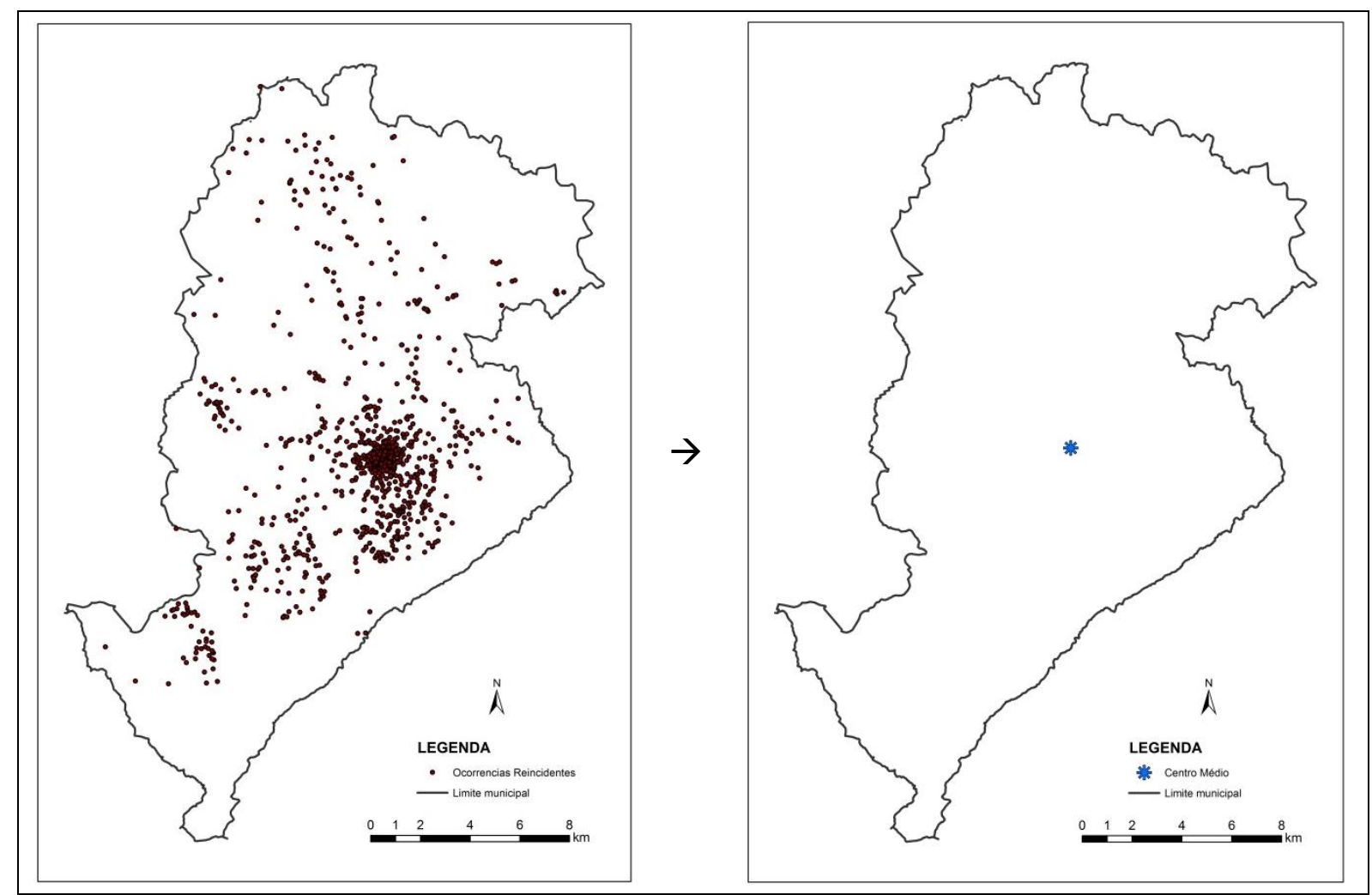

Fonte: Elaborado pelos autores.

\section{Distância Padrão ou Raio Padrão}

A "distância padrão $l^{2}$ ou raio padrão" refere-se a uma medida de dispersão dos pontos com distribuição bidimensional em relação ao centro médio, de maneira análoga ao desvio padrão em relação à media em distribuições unidimensionais.

Matematicamente, a distância padrão representa o desvio padrão das distâncias de cada ponto com o centro médio da distribuição.

O cálculo da distância padrão $I^{2}$ é realizado por meio da equação a seguir:

$$
l^{2}=\sqrt{\frac{\sum_{i=1}^{n} d_{i}^{2}}{N}}
$$

Onde $(d i)$ é a distância entre cada ponto i e o centro médio $\mathrm{Cm}$ da distribuição, e Né a quantidade de pontos no arranjo espacial.

Quanto maiores os valores de $l^{2}$, mais espalhados estarão os pontos em relação ao $\mathrm{Cm}$ e, quanto menores os valores de $\mathrm{l}^{2}$, mais agregados em relação ao $\mathrm{Cm}$. Assim, a distância padrão é uma medida de dispersão do arranjo de pontos no espaço geográfico (FERREIRA, 2014, p. 138). 
Por meio da distância padrão, aliado à informação do padrão de dispersão de pontos, é possível prever se os eventos perpetrados por autores reincidentes ocorrem de maneira concentrada, ou seja, se há uma área delimitada para atuação, descrita pelo raio padrão, bem como analisar as características destas áreas (caso haja), como distância mínima e máxima de eventos em relação ao centro médio e à distância padrão, além de se poder avaliar se há uma variabilidade destes parâmetros por tipologia criminal.

Figura 3 - Distância padrão da distribuição de pontos

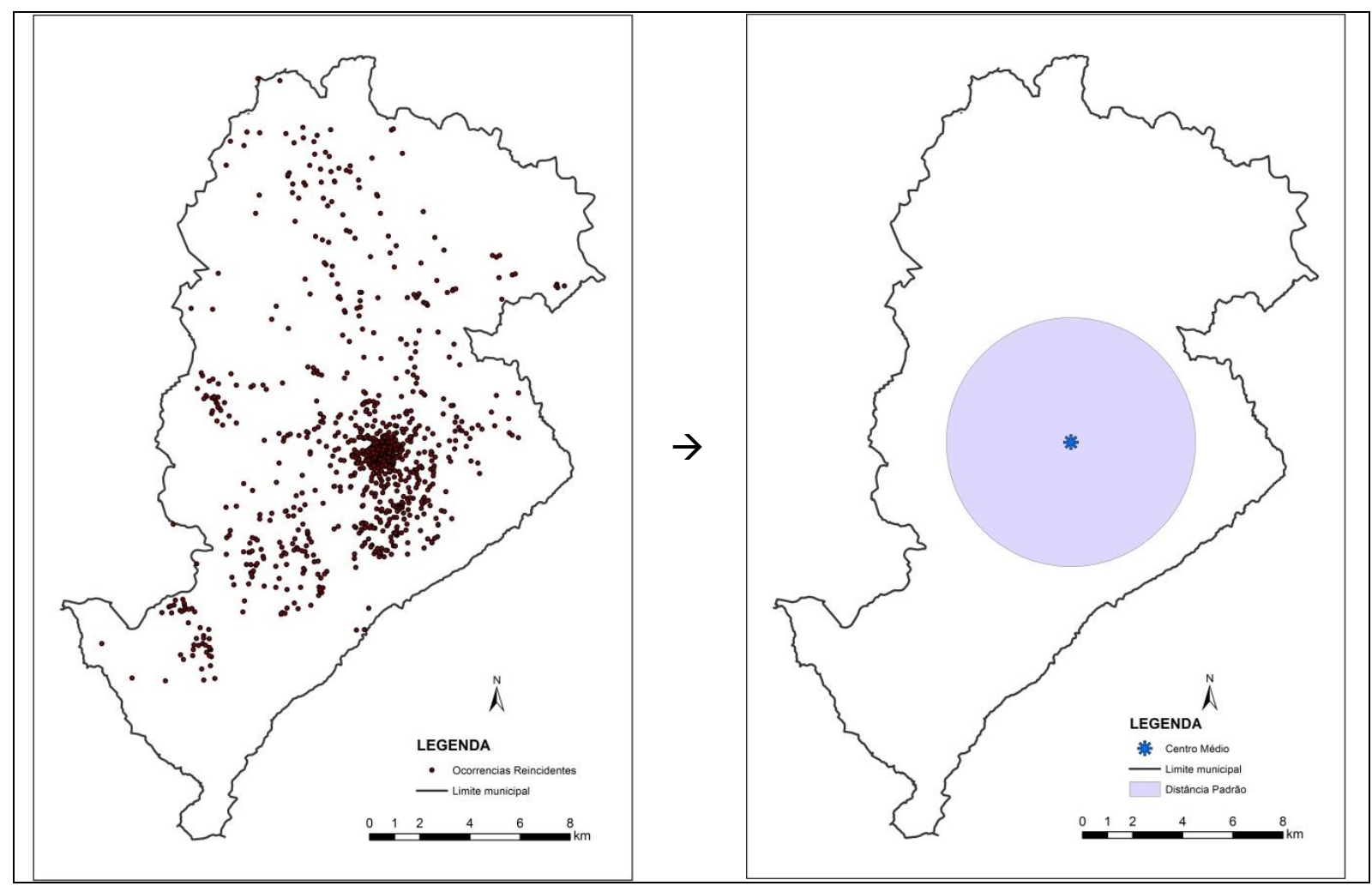

Fonte: Elaborado pelos autores.

\section{Distribuição Direcional - Elipse de Desvio Padrão}

Assim como o círculo descrito pela distância padrão, a elipse é capaz de identificar o centro de uma distribuição, bem como suas extensões espaciais, ou seja, a dispersão. Não obstante, uma elipse mede a forma e a orientação da distribuição resumindo a variância máxima e mínima ao longo dos eixos $x$ e $y$ (EBDON, 1988). Como resultado, a elipse pode explicar um arranjo não uniforme de eventos (LEFEVER, 1926; LEVINE, 2007). Essas diferenças estão ilustradas na Figura 4. 
Figura 4 - Exemplo comparativo dos modelos circular e elíptico

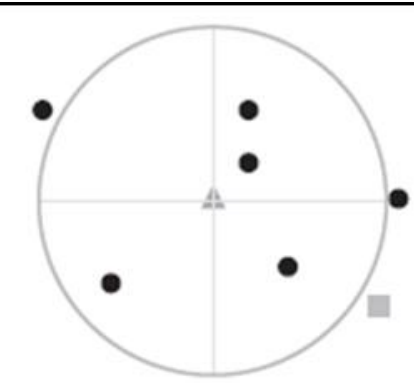

a. Circular Model Output

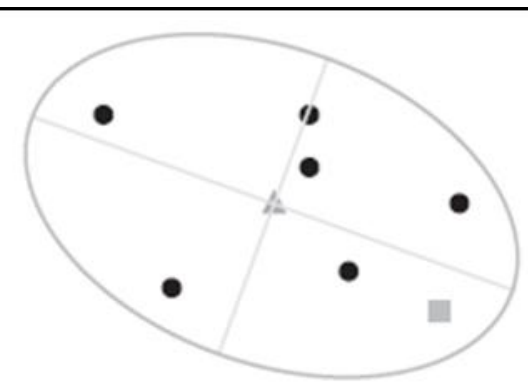

b. Elliptical Model Output

Figure 1. Example of circular (a) and elliptical (b) model output generated by Newton's geoforensic analysis. Each model is positioned over the geographic centre (triangle) of a theoretical distribution of crimes. The offender's residence (square) is captured by the elliptical model, but not the circle.

Fonte: Kent; Leitner (2007, p. 151).

Embora excessivamente simplista, pela Figura demonstra-se que uma elipse é mais capaz de explicar a distribuição irregular de eventos do que o modelo circular, ou seja, o modelo elíptico combina tanto a orientação quanto a variação na dispersão.

Kent e Leitner (2007) propõe que a relação espacial entre os locais da residência de um infrator e os de crime vinculados exibirá padrões espaciais e características consistentes com a paisagem subjacente. Consequentemente, um modelo de perfil geográfico capaz de medir a localização, a dispersão e a orientação das cenas do crime deve prever com mais precisão a localização residencial de um infrator em série. Além disso, como a paisagem tem um efeito determinista na distribuição do crime em série, a orientação elíptica produzida deve correlacionar-se com a orientação de características paisagísticas que coincidem com as extensões espaciais das cenas do delito. Essas medidas podem ser alcançadas usando um modelo de elipse de desvio padrão semelhante ao proposto por Lefever (1926), e posteriormente modificado por Levine (2007), Ebdon (1988) e Yuill (1971). Como tal, as hipóteses para a pesquisa dos autores podem ser resumidas em:

1) Os modelos de perfil geoforensico que usam a elipse de desvio padrão produzirão resultados mais precisos do que aqueles criados usando círculos.

2) A orientação de um perfil elíptico irá correlacionar-se com a orientação da paisagem física correspondente (KENT; LEITNER, 2007, p. 151, tradução nossa).

O principal objetivo da pesquisa de Kent e Leitner (2007) foi avaliar os efeitos da paisagem na aplicação do perfil geográfico. A análise "geoforensica" de Newton (1988) demonstrou como uma técnica de informação geográfica simples e intuitiva 
poderia ser utilizada para a investigação de um crime em série. $O$ aplicativo analisou sistematicamente uma distribuição de cenas de delito para prever o centro geográfico e estimar as extensões do espaço de atividade de um infrator em série. No entanto, as áreas de pesquisa circulares definidas por esta técnica de perfil, como com outras metodologias baseadas em círculos, assumem uma superfície isotrópica. No entanto, a pesquisa demonstra que os eventos de crime em série são distribuídos como fenômenos que são influenciados, em parte, pela paisagem física e cultural (BRANTINGHAM; BRANTINGHAM, 1981; ROSSMO, 1999; RENGERT; PIQUERO; JONES, 1999; KOCSIS; COOKSEY, 2002; HARRIES, 2006; CAPONE; NICHOLS, 1976; LEBEAU, 1987; CANTER et al., 2000). Com efeito, os padrões espaciais observados na distribuição são, na verdade, uma reflexão das irregularidades consistentes dentro da paisagem subjacente. Como tal, eles exibem características espaciais que podem ser analisadas geograficamente de acordo com sua localização, dispersão e orientação (KENT; LEITNER, 2007).

Assim, tem-se que a elipse de desvio padrão é uma técnica testada para análise de cenas criminais, em especial, para criminosos em série, que é objeto deste trabalho, e é mais apurada que os modelos circulares, pois permite identificar além do tamanho da distribuição, o seu formato, o que pode auxiliar numa análise geográfica da paisagem e sua influência na distribuição dos eventos criminais.

Cada elipse é determinada por meio de três parâmetros: ângulo de rotação, dispersão ao longo do maior eixo e dispersão ao longo do menor eixo. O eixo maior define a direção de máxima dispersão da distribuição e o menor eixo define a mínima dispersão (TARTARUGA, 2008).

No uso da técnica, pode-se definir o número de desvios: um, dois ou três. Para uma distribuição de tipo normal dos pontos dos dados ao redor do centro médio, tem-se que: uma elipse de um desvio padrão cobrirá, aproximadamente, $68 \%$ dos centroides do espaço analisado; de dois desvios padrão cobrirá, aproximadamente, 95\% dos centroides; e de três desvios padrão cobrirá, aproximadamente, $99 \%$ dos centroides (TARTARUGA, 2008).

A elipse de desvio padrão origina-se da distribuição bivariada que se caracteriza por dois tipos de desvio padrão, nas direções ortogonais $X$ (longitudes) e Y (latitudes) e que definem uma elipse, segundo Ebdon (1985):

Distribuição bivariada $=\sqrt{\frac{\sigma_{x}^{2}+\sigma_{y}^{2}}{2}}$ 
Em que: $\quad-\sigma_{x}$ : desvio padrão na direção X (longitudes);

- $\sigma_{y}$ : desvio padrão na direção $Y$ (latitudes).

A elipse de desvio padrão é calculada em duas etapas. Na primeira, a orientação dos eixos que define a elipse é calculada de modo que a soma dos quadrados das distâncias entre os pontos da distribuição e os eixos da elipse seja mínimo. Portanto, obtém-se o ângulo $(\theta)$ desta orientação por meio da seguinte equação:

$$
\theta=\operatorname{Arctan} \frac{\left\{\left(\sum_{i=1}^{n}\left(x_{i}-\bar{x}\right)^{2}-\sum_{i=1}^{n}\left(y_{i}-\bar{y}\right)^{2}\right)+\left[\left(\sum_{i=1}^{n}\left(x_{i}-\bar{x}\right)^{2}-\sum_{i=1}^{n}\left(y_{i}-\bar{y}\right)^{2}\right)^{2}+4\left(\sum_{i=1}^{n}\left(x_{i}-\bar{x}\right)\left(y_{i}-\bar{y}\right)\right)^{2}\right]^{1 / 2}\right\}}{2 \sum_{i=1}^{n}\left(x_{i}-\bar{x}\right)\left(y_{i}-\bar{y}\right)}
$$

Em que: $\quad-\theta$ : ângulo de rotação da elipse de desvio padrão;

- $x$ : coordenada X (longitude) do centro médio;

- $y$ : coordenada $Y$ (latitude) do centro médio;

- $x_{i}$ : coordenada $X$ (longitude) do centroide do evento "i";

- $y_{i}$ : coordenada Y (latitude) do centroide do evento "i";

- $n$ : número de centroides (eventos).

Assim, o eixo $Y$ é girado, no sentido horário, pelo ângulo $\theta$ (calculado anteriormente). Na segunda etapa para determinar a elipse, são calculados os dois desvios padrões $\left(\sigma_{X}, \sigma_{y}\right)$, utilizando os eixos $X$ e $Y$ girados, por meio das duas equações:

$$
\begin{gathered}
\sigma_{x}=\sqrt{\left\{2 \sum_{i=1}^{n}\left[\left(x_{i}-\bar{x}\right) \cos \theta-\left(y_{i}-\bar{y}\right) \sin \theta\right]^{2} / n-2\right\}} \\
\sigma_{y}=\sqrt{\left\{2 \sum_{i=1}^{n}\left[\left(x_{i}-\bar{x}\right) \sin \theta-\left(y_{i}-\bar{y}\right) \cos \theta\right]^{2} / n-2\right\}}
\end{gathered}
$$

$\sigma_{x}$ : desvio padrão na direção $X$ (longitudes);

$\sigma_{y}$ : desvio padrão na direção $Y$ (latitudes).

A elipse de desvio padrão define-se, além do centro médio (centro da elipse), pelos seguintes parâmetros:

- ângulo de rotação $=\theta$

- comprimento do eixo $X=2 \sigma_{x}$

- comprimento do eixo $Y=2 \sigma_{y}$ 
Para o presente trabalho, a elipse de desvio padrão foi utilizada para análise da forma em que se dá a distribuição dos fenômenos por indivíduo, agregando o aspecto direcional ao espaço de ação de cada autor, considerando-se, nesta análise, somente os fenômenos cometidos por cada indivíduo separadamente e avaliando-o conforme as características do cenário em que ocorreram. Ou seja, o objetivo da utilização desta técnica de análise foi buscar a explicação para o impacto da paisagem sobre a ocorrência do crime.

Foi utilizado como parâmetro de cálculo das elipses de desvio padrão o número de desvios igual a um, o que cobre, aproximadamente, $68 \%$ dos centroides do espaço analisado.

Figura 5 - Elipse de Desvio Padrão da distribuição de pontos

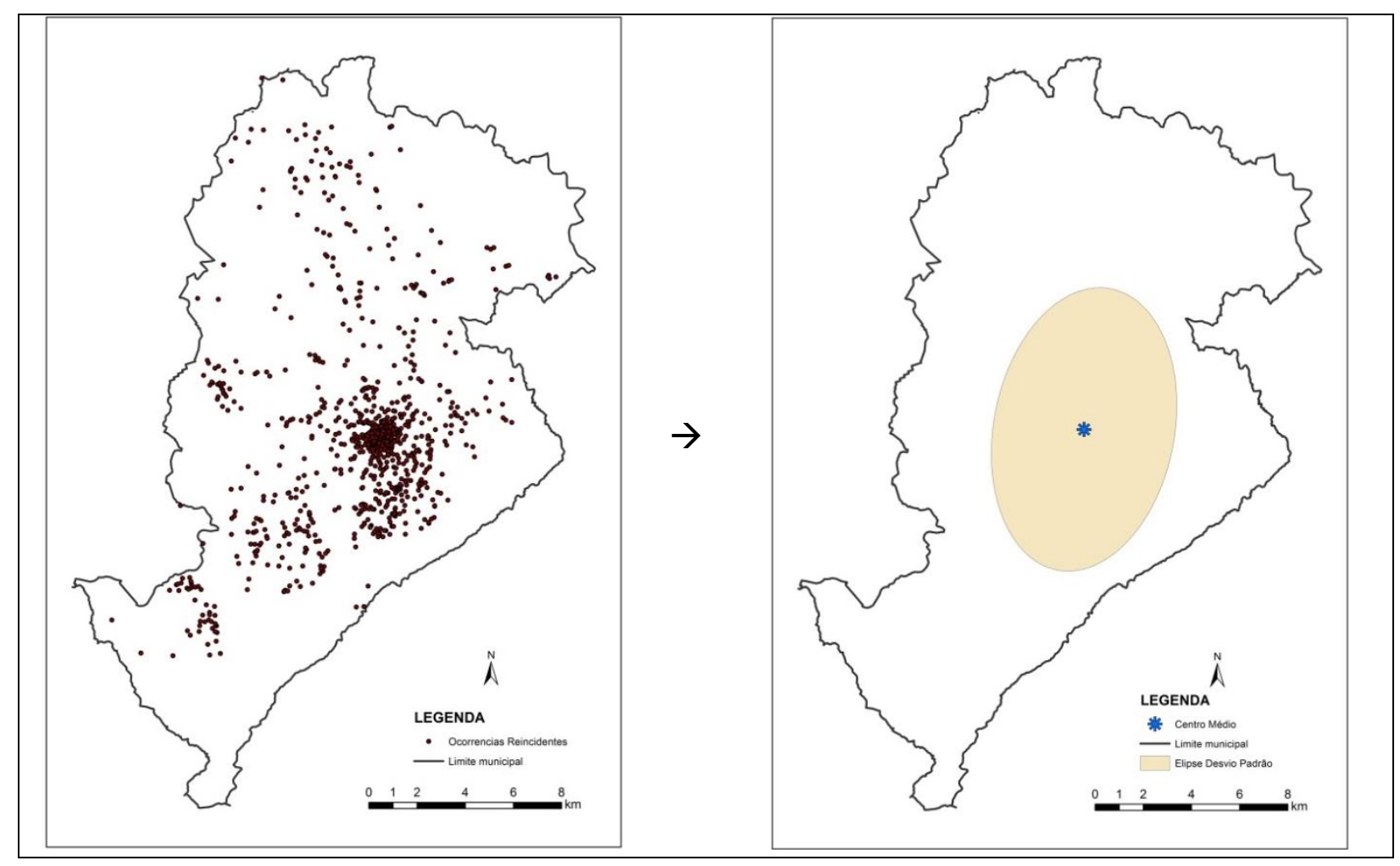

Fonte: Elaborado pelos autores.

A interpretação do ângulo de rotação da elipse pode ser ilustrada pela Figura 6: 
Figura 6 - Interpretação do ângulo de rotação da Elipse de Desvio Padrão

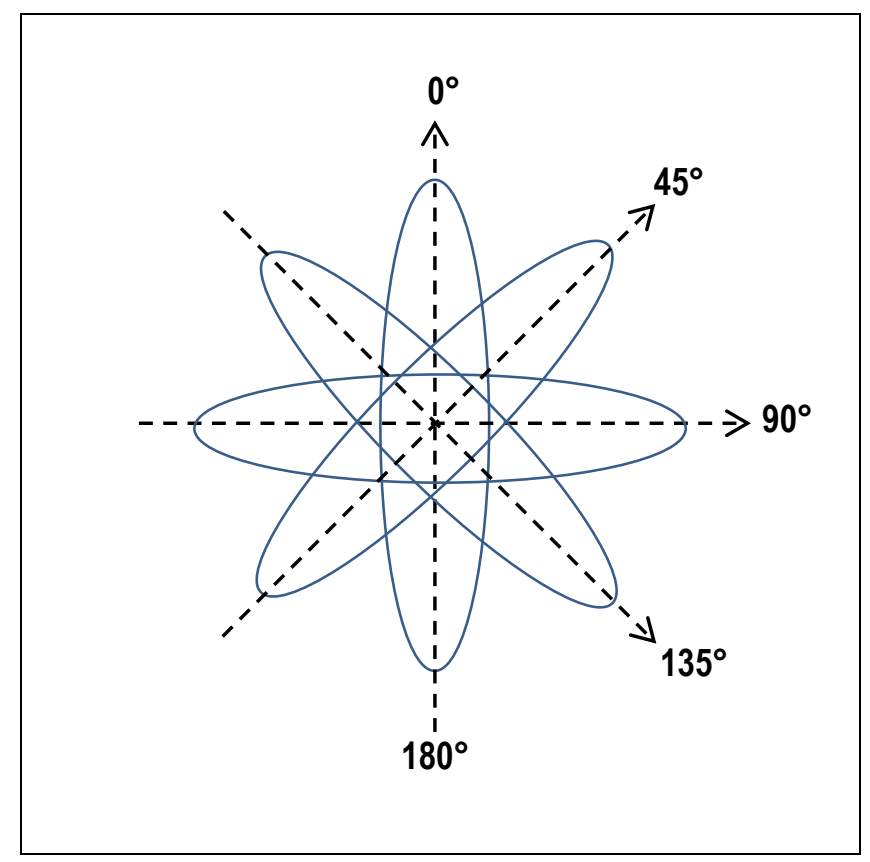

Fonte: Elaborado pelos autores.

Assim, o resultado de ângulo de rotação da elipse de desvio padrão igual a 0 은 indica uma orientação Norte-Sul do maior eixo e um ângulo 90ำ indica uma orientação Leste-Oeste, por exemplo.

\section{Material e Métodos}

A base de dados utilizada para o trabalho foi composta por Registros de Evento de Defesa Social (REDS), com delimitação espacial no município de Belo Horizonte no período de 01/01/2011 a 31/12/2013, perpetrados por indivíduos com no mínimo 04 boletins registrados como autores de delito.

Para cada autor de delito foi atribuído um código numérico sequencial, a fim de suprimir a identidade pessoal.

Para se atingir os objetivos propostos nesta pesquisa, foram coletados os seguintes dados:

a) número de criminosos em série: 114 indivíduos;

b) ocorrências perpetradas por criminosos em série: 1259 ocorrências;

As tipologias criminais obtidas como corpo da pesquisa, pelos requisitos propostos, constam da tabela a seguir: 
Tabela 1 - Frequência de eventos de criminosos em série por categoria (tipologia criminal) Belo Horizonte - 2011 a 2013

\begin{tabular}{|c|c|c|}
\hline \multirow{2}{*}{ Categoria } & \multicolumn{2}{|c|}{ Frequência } \\
\hline & Absoluta & Relativa \\
\hline Contra o Patrimônio & 796 & $63 \%$ \\
\hline Entorpecentes (Uso) & 111 & $9 \%$ \\
\hline Entorpecentes (Tráfico) & 98 & $8 \%$ \\
\hline Contravenção Penal & 94 & $7 \%$ \\
\hline Contra a Liberdade Individual & 61 & $5 \%$ \\
\hline Lesões Corporais & 37 & $3 \%$ \\
\hline Contra a Administração & 21 & $2 \%$ \\
\hline Armas & 9 & $1 \%$ \\
\hline Contra a vida & 8 & $1 \%$ \\
\hline Crime Trânsito & 8 & $1 \%$ \\
\hline Fraude & 7 & $1 \%$ \\
\hline Residual $^{*}$ & 9 & $1 \%$ \\
\hline TOTAL & 1259 & $100 \%$ \\
\hline
\end{tabular}

Fonte: Dados da Pesquisa.

Nota: *Categoria Residual contempla (04 eventos contra a Fé Pública; 03 eventos contra o Meio Ambiente; 1 evento contra a Honra e 1 evento de periclitação da vida).

A partir do banco de dados, as análises centrográficas foram realizadas por meio do software Arc Gis e os resultados foram expressos em tabelas, gráficos e mapas.

\section{Resultados e Discussões}

Nessa análise, buscou-se compreender as características individuais da atuação de cada um dos autores de eventos reincidentes com a finalidade de buscar padrões explicativos para o comportamento criminal contumaz.

\section{Centro Médio}

Um dos parâmetros para se analisar a concentração dos eventos foi o centro médio das ocorrências. Essa variável representa a média aritmética das coordenadas de longitude e latitude e teve por objetivo permitir a descrição da concentração dos eventos, além de servir de base para análise do "espaço de ação" por meio da "distância padrão" e da distribuição direcional, pela "elipse de desvio padrão". 
No mapa a seguir (Figura 7), estão representados os centros médios de todas as ocorrências de criminosos em série individualmente e o centro médio das ocorrências gerais em Belo Horizonte.

Figura 7 - Mapa de Centro Médio de Ocorrências por autor criminoso habitual - Belo Horizonte - 2011-2013

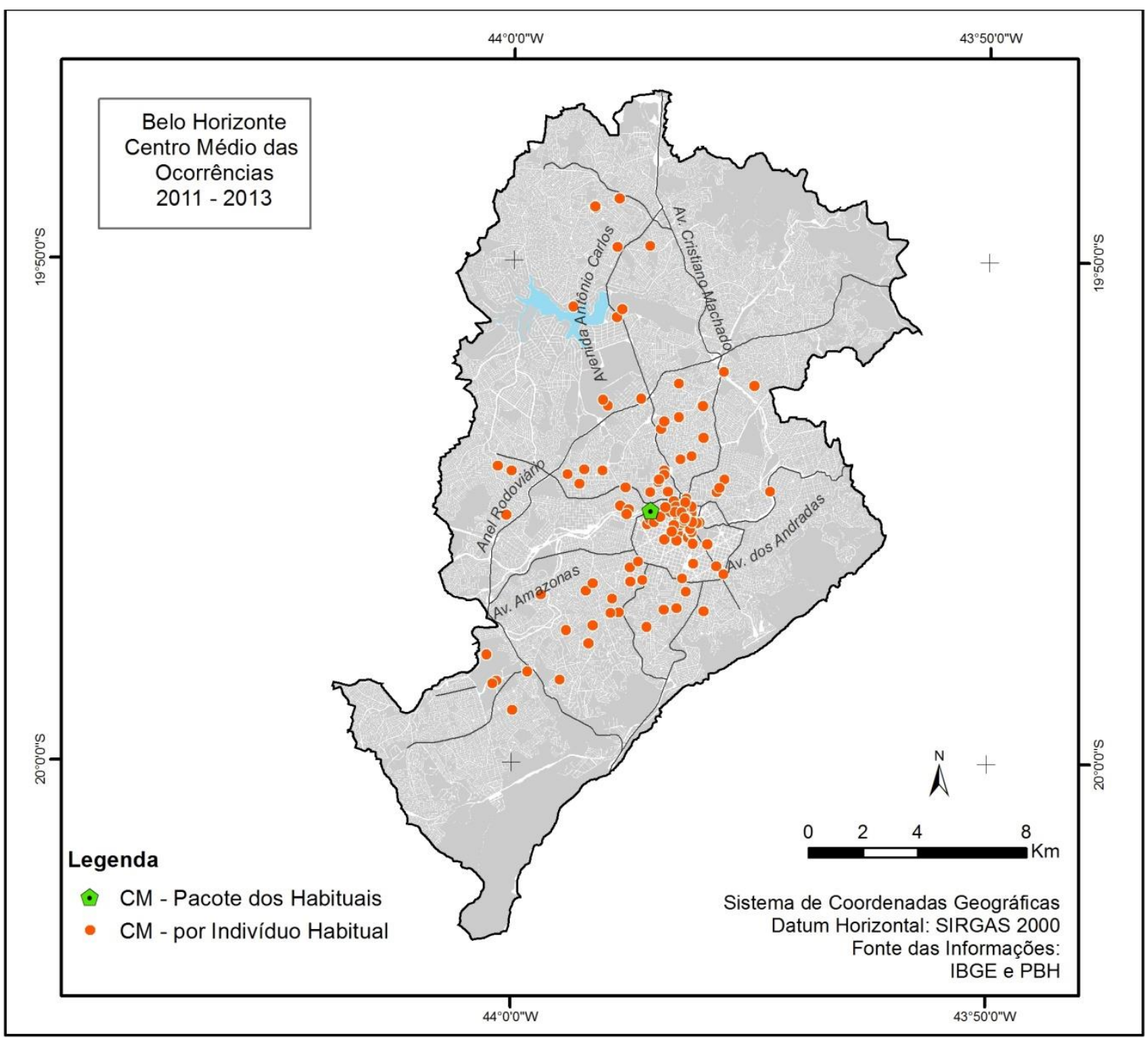

Fonte: Dados da Pesquisa.

Pelo mapa, verifica-se que há uma concentração de centros médios $(\mathrm{Cm})$ de ocorrências no nível individual, com aproximação do $\mathrm{Cm}$ geral. A maior parte dos $\mathrm{Cm}$ concentra-se próximo da região central de Belo Horizonte, o que pode ser explicado pelo uso e ocupação do solo da região, vez que engloba importantes atividades administrativas, instituições financeiras e unidades comerciais, que definem um potencial de atratores para o crime. 


\section{Distância Padrão}

Outra medida centrográfica analisada foi a distância padrão, que se refere à dispersão dos pontos com distribuição bidimensional em relação ao centro médio. No mapa, a seguir, estão representadas distâncias padrão para cada um dos criminosos em série. Este valor refere-se ao diâmetro da área que tem como centro o $\mathrm{Cm}$ de ocorrências de cada um dos indivíduos.

Figura 8 - Mapa de Distância Padrão de Ocorrências por autor criminoso habitual - Belo

$$
\text { Horizonte - 2011-2013 }
$$

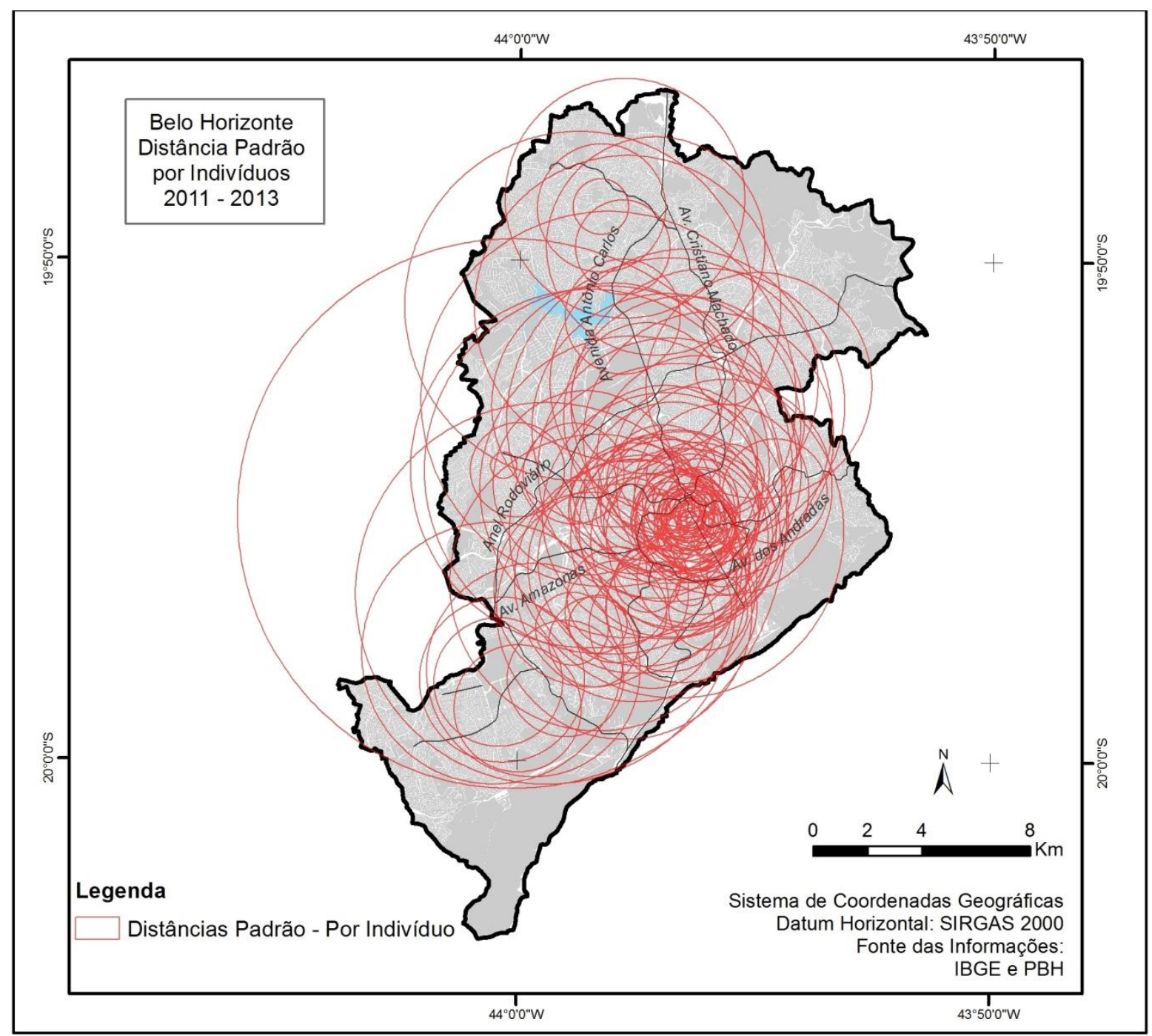

Fonte: Dados da Pesquisa.

Em termos da distância padrão de ocorrências em relação ao Centro Médio, obteve-se como resultado o menor valor de 139,37 metros e o maior valor de 10128,03 metros e como média de distância 2623,61 metros.

Os dados encontram-se descritos no Gráfico 1. 
Gráfico 1 - Distância Padrão por Indivíduo Criminoso Habitual - Belo Horizonte - 2011-2013

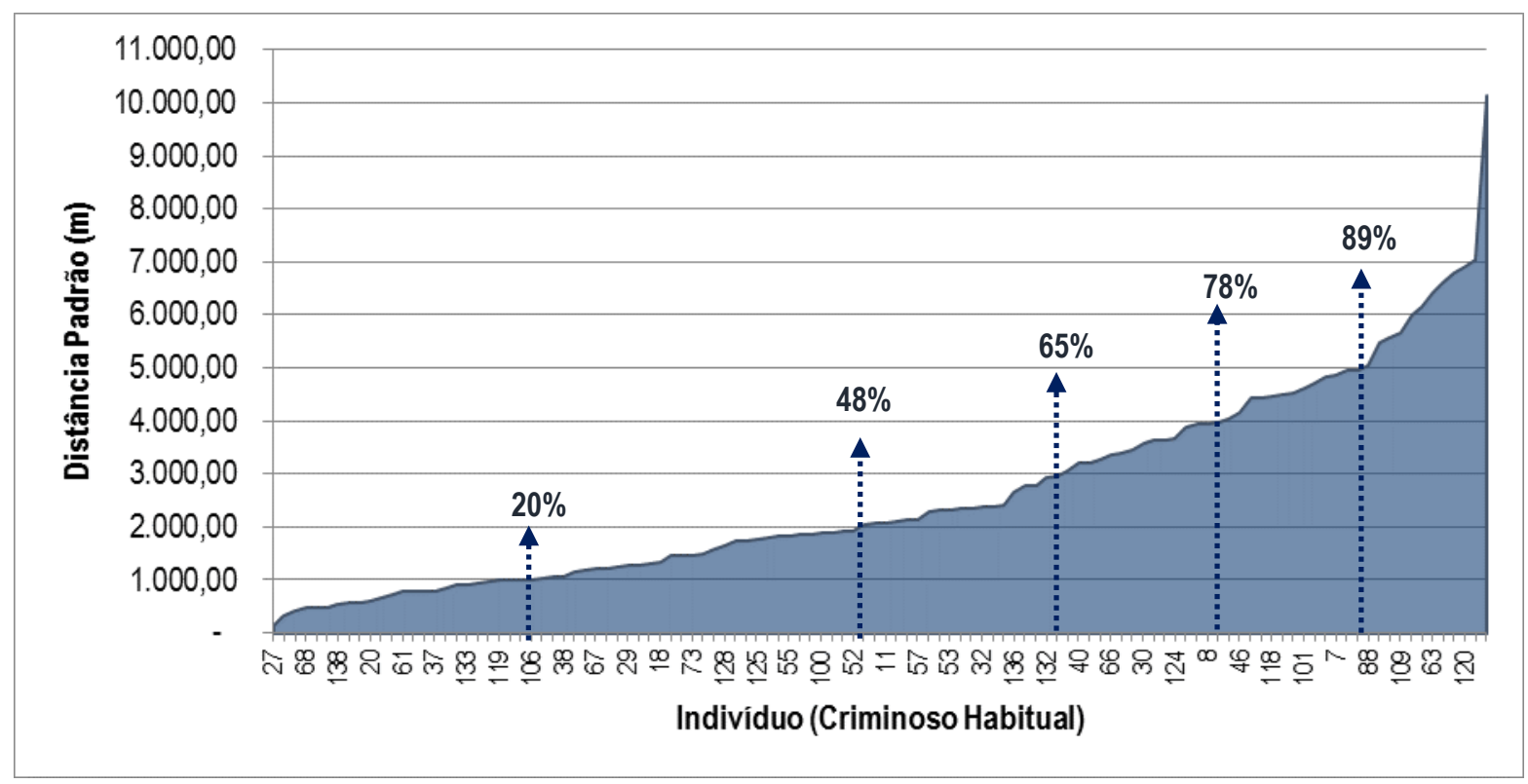

Fonte: Dados da Pesquisa.

A fim de buscar padrões em termos das características da área de atuação, verificou-se a frequência acumulada dos indivíduos em termos da distância padrão de distribuição dos eventos em termos do $\mathrm{Cm}$.

Tabela 2 - Frequência de indivíduos por distância padrão - Belo Horizonte - 2011-2013

\begin{tabular}{c|c|c|c}
\hline \multirow{2}{*}{$\begin{array}{c}\text { Distância } \\
\text { (faixa) }\end{array}$} & \multicolumn{3}{|c}{ Frequência } \\
\cline { 2 - 4 } & Absoluta & Percentual & Acumulado \\
\hline Até $500 \mathrm{~m}$ & 6 & $5 \%$ & $5 \%$ \\
De 501 a 1000 & 17 & $15 \%$ & $20 \%$ \\
1001 a $1500 \mathrm{~m}$ & 17 & $15 \%$ & $35 \%$ \\
1501 a $2000 \mathrm{~m}$ & 15 & $13 \%$ & $48 \%$ \\
2001 a $2500 \mathrm{~m}$ & 14 & $12 \%$ & $61 \%$ \\
2501 a 3000 m & 5 & $4 \%$ & $65 \%$ \\
3001 a 3500 m & 7 & $6 \%$ & $71 \%$ \\
3501 a $4000 \mathrm{~m}$ & 8 & $7 \%$ & $78 \%$ \\
4001 a $4500 \mathrm{~m}$ & 6 & $5 \%$ & $83 \%$ \\
4501 a $5000 \mathrm{~m}$ & 7 & $6 \%$ & $89 \%$ \\
5001 a $5500 \mathrm{~m}$ & 2 & $2 \%$ & $91 \%$ \\
5501 a $6000 \mathrm{~m}$ & 3 & $3 \%$ & $94 \%$ \\
Acima de 6000 & 7 & $6 \%$ & $100 \%$ \\
\hline
\end{tabular}

Fonte: Dados da Pesquisa.

Conforme se vê, há uma área restrita de atuação em termos de distância em relação ao centro médio para uma parcela considerável dos autores reincidentes. Cumulativamente, 48\% dos agentes (55 indivíduos) possuem distância padrão dos 
eventos menor que 2000 metros, ou seja, têm uma área de atuação bem restrita. 65\% (74 indivíduos) atuam numa área de até $3 \mathrm{~km}$; 78\% (89 indivíduos) em até 4 km; 89\% até $5 \mathrm{~km}$ (102 indivíduos) e somente 11\% dos autores reincidentes (12 indivíduos) tiveram distância padrão acima de $5 \mathrm{~km}$.

A maior parte das distâncias padrão (55\% dos criminosos em série) ocorreu numa faixa entre 501 e 2500 m a partir do Centro Médio individual. Pode-se inferir, portanto, que, para a maioria dos criminosos em série estudados tem seus eventos criminais cometidos numa faixa restrita de área delimitada por um diâmetro de 2,5 km a partir de um ponto de ancoragem (anchor point) que é o Centro Médio das ocorrências.

\section{Elipse de Desvio Padrão}

A distribuição direcional (elipse de desvio padrão) agrega o aspecto do formato da alocação espacial dos eventos, representando, também, a orientação, além da densidade dos pontos. Dessa forma, contribui para a identificação de tendência de distribuição dos pontos e permite uma análise que leve em consideração a paisagem em que os fenômenos ocorrem. 
Figura 9 - Mapa de Elipses de Desvio Padrão de Ocorrências por autor criminoso habitual Belo Horizonte - 2011-2013

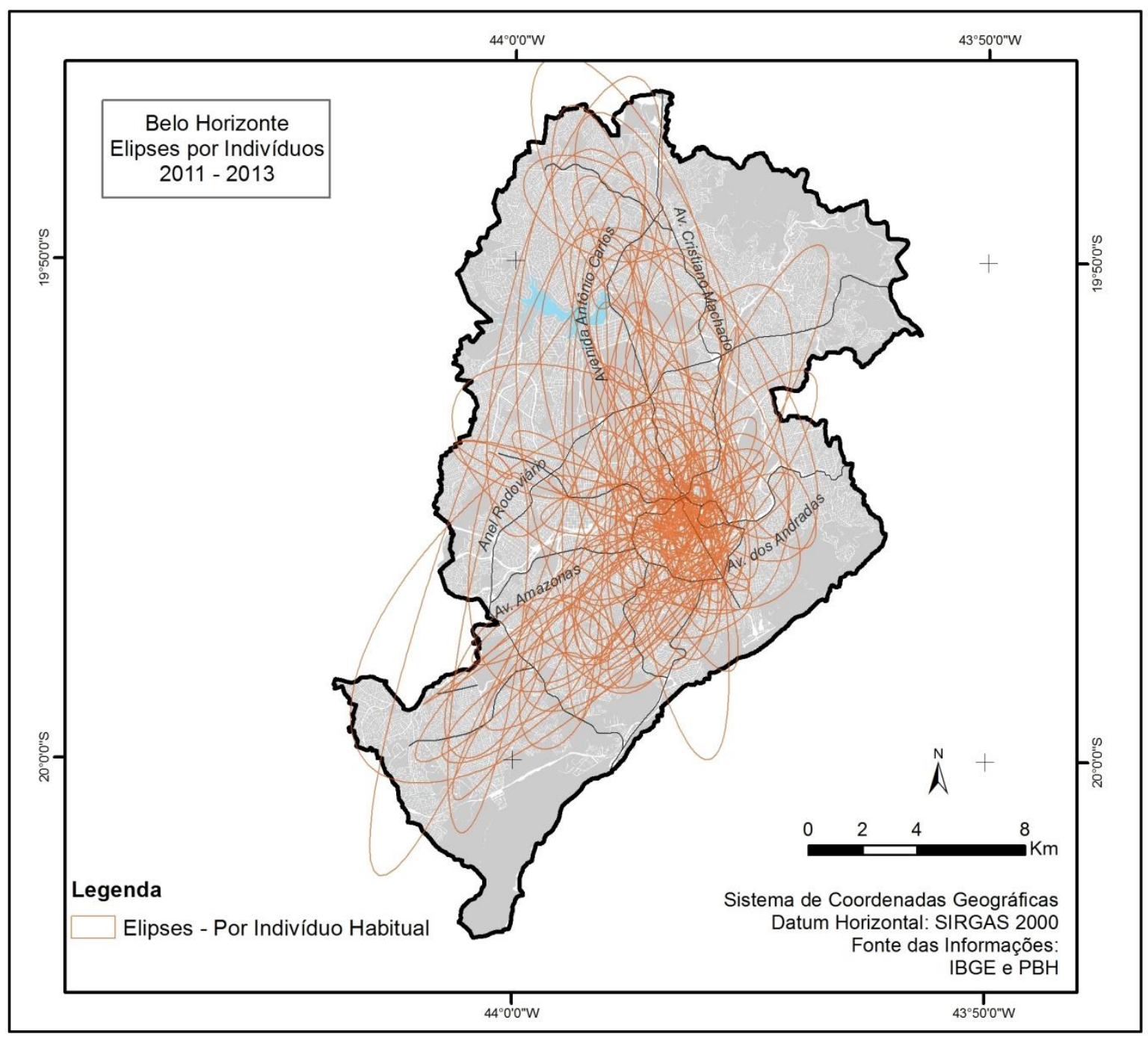

Fonte: Dados da Pesquisa.

Conforme opção metodológica realizada, as elipses foram construídas com um desvio padrão, quer dizer, as elipses compreendem $68 \%$ dos centroides do espaço analisado. Por esse critério, observa-se a abrangência das elipses com grande concentração na região central de Belo Horizonte.

Com a finalidade de correlacionar a distribuição dos eventos com a paisagem urbana, verificou-se a dispersão ao longo do maior eixo e do ângulo de rotação.

Essa dispersão cobre a maior parte dos principais eixos viários de Belo Horizonte, permitindo inferir que os caminhos (paths) representam um importante elemento de análise na distribuição de eventos criminais de autores em série.

Em termos de ângulo de rotação das elipses, para viabilizar a análise, agrupou-se por faixas de ângulos, conforme Tabela a seguir: 
Tabela 3 - Distribuição dos ângulos de rotação das elipses de desvio padrão dos crimes cometidos por criminosos em série - Belo Horizonte - 2011-2013

\begin{tabular}{ccc}
\hline Faixa & Quantidade & $\%$ \\
\hline$\theta \leq 45^{\circ}$ & 40 & $35 \%$ \\
$45^{\circ}<\theta \leq 90^{\circ}$ & 20 & $18 \%$ \\
$90^{\circ}<\theta \leq 135^{\circ}$ & 15 & $13 \%$ \\
$135^{\circ}<\theta \leq 180^{\circ}$ & 39 & $34 \%$ \\
\hline
\end{tabular}

Fonte: Dados da Pesquisa.

Para se analisar o ângulo de rotação, elaborou-se a Figura 10, a seguir:

Figura 10 - Representação das áreas cobertas pelas elipses conforme ângulos de rotação

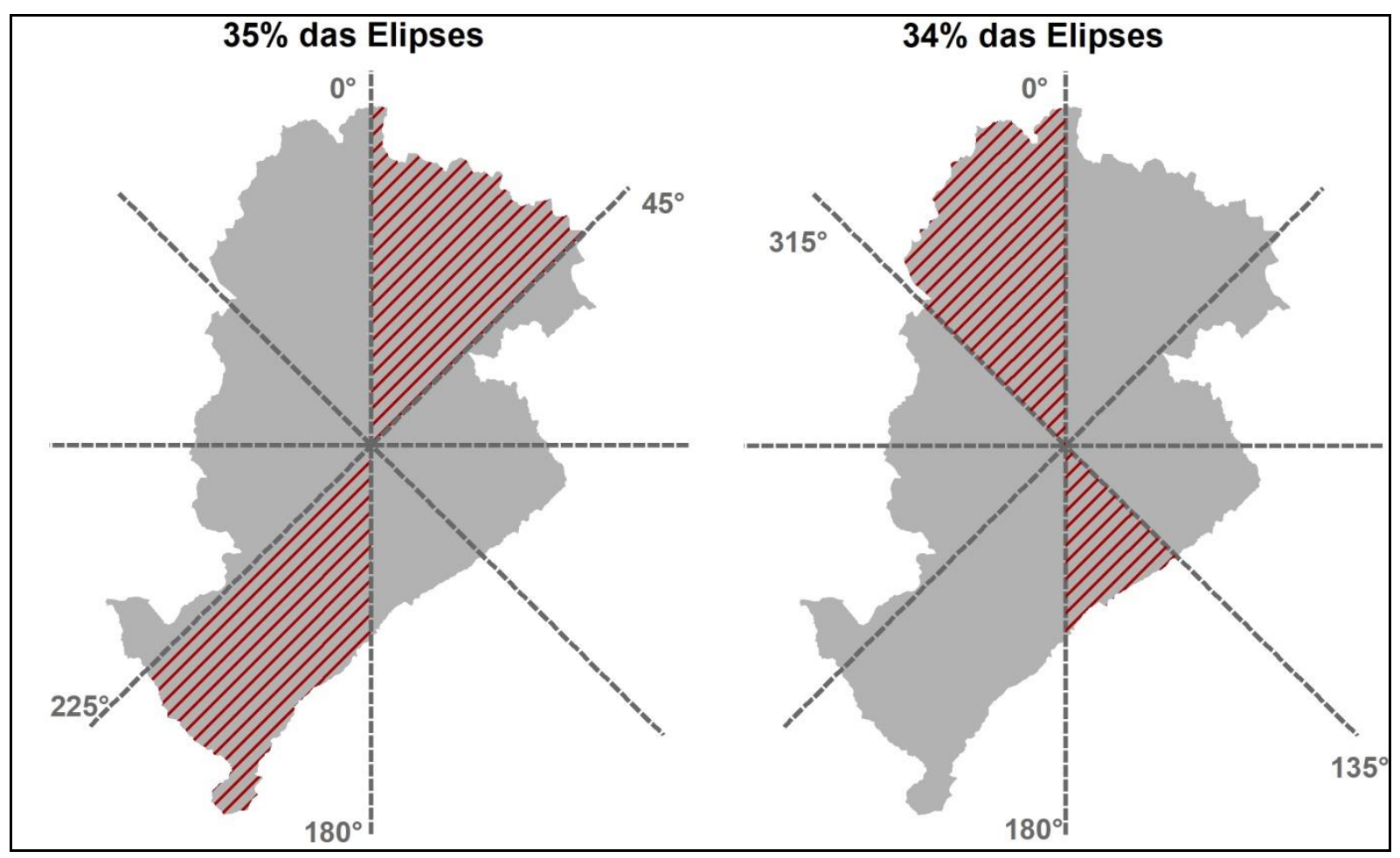

Fonte: Elaborado pelos autores.

Assim, o espalhamento dos eventos que define o formato das elipses, ocorre principalmente no sentido Norte-Sul da cidade, possuindo o efeito de atração da região central (hipercentro), e acompanha o sentido dos eixos viários principais do vetor Norte precipuamente, Av. Cristiano Machado e Av. Antônio Carlos/Av. Pedro I. A distribuição de facilities por uso e ocupação do solo de usos comerciais, instituições bancárias e de ensino, constam na Figura 11. 
Figura 11 - Distribuição de facilities por uso e ocupação do solo - Belo Horizonte - 2013

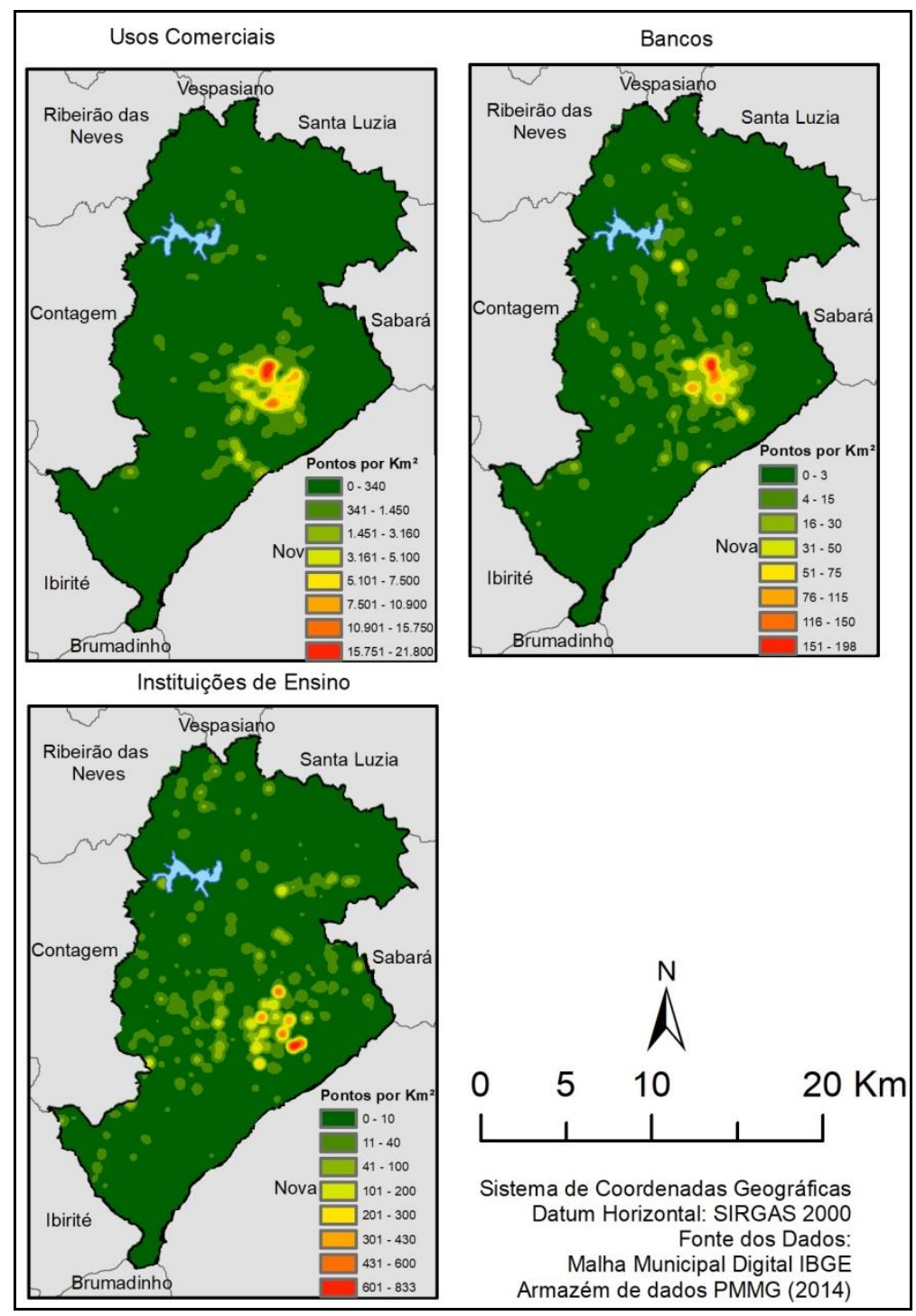

Fonte: Elaborado pelos autores com base em dados da Prefeitura de Belo Horizonte.

Conforme o mapa, verifica-se que há concentração de facilities na região do hipercentro de Belo Horizonte, local de maior concentração de espaço de ação de criminosos em série. A concentração de facilities é, portanto, fator explicativo da aglomeração de atuações criminais, pois, de acordo com as teorias do padrão de crime e das atividades de rotina, essas regiões reúnem grande número de pessoas que podem ser vítimas em potencial, as quais se deslocam para a realização de atividades lícitas diárias.

Assim, as facilites representam um tipo especializado de "nós": atrativos de crimes (crime attractors). 


\section{Considerações Finais}

Verificou-se com o trabalho as medidas de centralidade para combinar 0 espaço de ação dos autores de delitos à paisagem urbana. Observou-se a concentração de centros médios $(\mathrm{Cm})$ de ocorrências no nível individual, com aproximação do $\mathrm{Cm}$ geral concentrados na região do hipercentro de Belo Horizonte, o que pode ser explicado pelo uso e ocupação do solo da região, vez que engloba importantes atividades administrativas, instituições financeiras e unidades comerciais, que definem um potencial de atratores para o crime.

Outro aspecto do comportamento espacial criminal foi o alcance criminal. Em termos da distância padrão dos eventos, para a maioria dos indivíduos criminosos em série, o espaço de ação esteve delimitado numa faixa restrita delimitada por um diâmetro de $2,5 \mathrm{~km}$ a partir do Centro Médio, que representa um ponto de ancoragem.

Com relação à distribuição dos eventos e sua relação om a paisagem urbana, verificou-se a dispersão ao longo do maior eixo e o ângulo de rotação das elipses de desvio padrão. Este parâmetro coincide com os principais eixos viários de Belo Horizonte, permitindo inferir que os caminhos (paths) representam um importante elemento no comportamento criminal, corroborando com as teorias de padrão do crime e de atividades rotineiras.

Verificou-se, ainda, que os resultados corroboram e complementam com pesquisas que analisam a distribuição dos eventos criminais e os atratores para o crime. Em termos de distribuição espacial, há a mesma tendência de concentração dos delitos em locais determinados pelo uso e ocupação do solo para os crimes gerais e os cometidos em nível individual.

\section{REFERÊNCIAS}

ANDERSON, Amy L.; HUGHES, Lorine A. Exposure to situations conducive to delinquent behavior: The effects of time use, income, and transportation. Journal of Research in Crime and Delinquency, v. 46, n. 1, p. 5-34, 2009.

BEATO, C. et al. Crime e Estratégias de Policiamento em Espaços Urbanos. DADOS Revista de Ciências Sociais, Rio de Janeiro, v. 51, n.3, p. 687-717, 2008. 
BRANTINGHAM, P.; BRANTINGHAM, P. Notes on the geometry of crime. In:

BRANTINGHAM, P.; BRANTINGHAM, P. Environmental Criminology. p. 27-54. Prospect Heights, IL: Waveland, 1991.

BRANTINGHAM, P.; BRANTINGHAM, P.. Environmental criminology. Beverly Hills, CA: Sage. In: Canter, D. Confusing operational predicaments and cognitive explorations:

Comments on Rossmo and Snook et al. Applied Cognitive Psychology, 19, 663-668, 1981.

BRANTINGHAM, P.; BRANTINGHAM, P.. Nodes, paths and edges: Considerations on the complexity of crime and the physical environment. Journal of Environmental Psychology, 13, 3-28, 1993.

BRANTINGHAM, P.; BRANTINGHAM, P. Criminality of place, European journal on criminal policy and research, v. 3, n. 3, p. 5-26, 1995.

CANTER, D.; LARKIN, G.. The environmental range of serial rapists. Journal of ENVIRONMENTAL Psychology, 13, 63-69, 1993.

CANTER, David et al. Predicting serial killers' home base using a decision support system. Journal of quantitative criminology, v. 16, n. 4, p. 457-478, 2000.

CANTER, D. V.; HODGE, S. Mental mapping. Criminal's mental maps. In L. S. Turnbull, E. H. Hendrix, \& B. D. Dent (Eds.), Atlas of crime: Mapping the criminal landscape (pp. 186191). Phoenix, Arizona: Onyx Press, 2000.

CANTER, David; SHALEV, Karen. Putting crime in its place: Psychological process in crime site selection. Principles of geographical offender profiling, p. 259-269, 2008.

CANTER, David V.; YOUNGS, Donna E. Principles of geographical offender profiling. Ashgate Publishing Ltd, 2008.

CAPONE, Donald L.; NICHOLS JR, Woodrow W. Urban structure and criminal mobility. American Behavioral Scientist, v. 20, n. 2, p. 199-213, 1976.

CLARK, A. N. The new Penguin dictionary of geography. London: Penguin Books, 1990.

CLARKE, R.; FELSON, M. Routine Activity and Rational Choice. London: Transaction, 1993.

CORNISH, D. B.; CLARKE, R. V. The reasoning criminal: Rational choice perspectives on offending. New York: Springer-Verlag, 1986.

CORNISH, D. B.; CLARKE, R. V. The reasoning criminal: Rational choice perspectives on offending. New York: Springer-Verlag, 1986.

EBDON, D. Statistics in geography (2nd ed.). Oxford, UK: Blackwell Publishing, Ltd, 1988.

FARIA, Antonio Hot Pereira de; ALVES, Diego Filipe Cordeiro; ABREU, João Francisco. Análise espacial aplicada ao estudo do crime: uma abordagem exploratória da distribuição dos atrativos para o crime no espaço urbano de Belo Horizonte / Spatial analysis applied to study of crime: an exploratory approach to the distribution of attractions for crime in the urban space of Belo Horizonte. Caderno de Geografia, Belo Horizonte, v. 28, n. 55, p. 1006-1020, out. 2018. ISSN 2318-2962. Disponível em:

$<$ http://periodicos.pucminas.br/index.php/geografia/article/view/17014>. Acesso em: 02 jan. 2019. doi: https://doi.org/10.5752/P.2318-2962.2018v28n55p1006-1020. 
FELSON, M.; GOTTFREDSON, M. Social indicators of adolescent activities near peers and parents. Journal of Marriage and the Family, p. 709-714, 1984.

FERREIRA, Marcos César. Iniciação À Análise Geoespacial - Teoria, Técnicas e Exemplos Para Geoprocessamento. São Paulo: Editora UNESP, 2014.

FRANK, Richard et al. Power of criminal attractors: modeling the pull of activity nodes. Journal of Artificial Societies and Social Simulation, v. 14, n. 1, p. 6, 2011. Disponível em: http://jasss.soc.surrey.ac.uk/14/1/6.html. Acesso em: 27 Fev. 17.

HARRIES, Keith. Extreme spatial variations in crime density in Baltimore County, MD. Geoforum, v. 37, n. 3, p. 404-416, 2006.

JAKLE, John A.; BRUNN, Stanley D.; ROSEMAN, Curtis C. Human spatial behavior: a social geography. Duxbury Press, 1976.

KENT, Joshua; LEITNER, Michael. Efficacy of standard deviational ellipses in the application of criminal geographic profiling. Journal of Investigative Psychology and Offender Profiling, v. 4, n. 3, p. 147-165, 2007.

KOCSIS, R. N., \& COOKSEY, R. W. Criminal psychological profiling of serial arson crimes. International Journal of Offender Therapy and Comparative Criminology, 46, 631-656. 2002.

LADD, Florence C. Black youths view their environment: Neighborhood maps. Environment and Behavior, v. 2, n. 1, p. 74-99, 1970.

LEBEAU, James $L$. The methods and measures of centrography and the spatial dynamics of rape. Journal of Quantitative Criminology, v. 3, n. 2, p. 125-141, 1987.

LEFEVER, D. Welty. Measuring geographic concentration by means of the standard deviational ellipse. American Journal of Sociology, v. 32, n. 1, p. 88-94, 1926.

LEVINE, Ned et al. CrimeStat: a spatial statistics program for the analysis of crime incident locations. Ned Levine \& Associates, Houston, TX, and the National Institute of Justice, Washington, DC, 2007.

LEWIN, Kurt. Field Theory in Social Science. New York: Harper and Row, 1951.

LYNCH, Kevin. The image of the city. MIT press, 1960.

NEWTON, M. B. Geographical discovery of the residence of an unknown dispersing localized serial murder. Unpublished manuscript. Baton Rouge, LA: Louisiana State University, 1988.

PAULSEN, Derek. Human versus machine: A comparison of the accuracy of geographic profiling methods. Journal of Investigative Psychology and Offender Profiling, v. 3, n. 2, p. 77-89, 2006.

PAULSEN, Derek J.; ROBINSON, Matthew B. Spatial aspects of crime: Theory and practice. Allyn \& Bacon, 2004.

RENGERT, George F.; PIQUERO, Alex R.; JONES, Peter R. Distance decay reexamined. Criminology, v. 37, n. 2, p. 427-446, 1999.

RICH, Tom; SHIVELY, Michael. A methodology for evaluating geographic profiling software: final report. Abt Associates Inc., Cambridge, 2004. 
ROBINSON, William S. Ecological correlations and the behavior of individuals. International journal of epidemiology, v. 38, n. 2, p. 337-341, 2009.

ROSSMO, D. Kim. Geographic profiling. Boca Raton, FL: CRC Press, 1999

SMITH, Christopher J.; PATTERSON, Gene E. Cognitive mapping and the subjective geography of crime. Crime: A spatial perspective, p. 205-218, 1980.

SNOOK, Brent et al. On the complexity and accuracy of geographic profiling strategies. Journal of Quantitative Criminology, v. 21, n. 1, p. 1-26, 2005.

TARTARUGA, Iván G. Peyré. Análise espacial da centralidade e da dispersão da população do Estado do Rio Grande do Sul de 1970 a 2000: notas preliminares. Encontro Nacional de Estudos Populacionais, v. 16, 2008.

WARR, M. Making delinquent friends: Adult supervision and children's affiliations, Criminology, v. 43, n. 1, p. 77-106, 2005.

WILES, Paul; COSTELLO, Andrew. The road to nowhere: the evidence for travelling criminals. London: Research, Development and Statistics Directorate, Home Office, 2000.

WOLPERT, Julian. Behavioral aspects of the decision to migrate. Papers in Regional Science, v. 15, n. 1, p. 159-169, 1965.

YUILL, Robert S. The standard deviational ellipse; an updated tool for spatial description. Geografiska Annaler. Series B, Human Geography, v. 53, n. 1, p. 28-39, 1971.

\section{NOTAS DE AUTOR}

\section{CONTRIBUIÇÃO DE AUTORIA}

Antônio Hot Pereira de Faria - Concepção. Formulação e evolução de objetivos e metas abrangentes da pesquisa. Coleta de dados, Formulação do Banco de Dados, Análise de dados, Criação de modelos metodológicos. Discussão dos resultados. E laboração do manuscrito, revisão e aprovação da versão final do trabalho.

Alexandre Magno Alves Diniz - Condução da pesquisa e processo de investigação. Participação ativa da discussão dos resultados; Revisão e aprovação da versão final do trabalho.

Diego Filipe Cordeiro Alves - Criação de modelos metodológicos. Representação dos dados. Participação ativa da discussão dos resultados.

\section{FINANCIAMENTO}

Coordenação de Aperfeiçoamento de Pessoal de Nível Superior.

\section{CONSENTIMENTO DE USO DE IMAGEM}

Não se aplica. 
Não se aplica.

LICENÇA DE USO

Este artigo está licenciado sob a Licença Creative Commons CC-BY. Com essa licença você pode compartilhar, adaptar, criar para qualquer fim, desde que atribua a autoria da obra.

\section{HISTÓRICO}

Recebido em: 06-10-2019

Aprovado em: 28-03-2020 